\title{
KEKERASAN SEKSUAL PADA ANAK: TELAAH RELASI PELAKU KORBAN DAN KERENTANAN PADA ANAK
}

\author{
Diesmy Humaira B, \\ Nurur Rohmah, \\ Nuril Rifanda, \\ Kunti Novitasari, \\ Ulya Diena $\mathrm{H}$, \\ Fathul Lubabin Nuqul \\ Fakultas Psikologi \\ Universitas Islam Negeri (UIN)Maulana Malik Ibrahim Malang \\ Jl. Gajayana 50 Malang Telp. 0341-558916
}

\begin{abstract}
Abstrak - Kekerasan seksual pada anak marak terjadi di masyarakat. Penelitian ini bertujuan untuk mendeskripsikan kejadian kekerasan seksual pada anak, relasi antara pelaku-korban serta modus yang dilakukan,serta menimbang kerentanan pada anak-anak sebagai korban. Penelitian ini menganalisa 16 Berita Acara Persidangan (BAP) dari Directori Putusan Mahkamah Agung Indonesia. Dari 16 kasus yang dianalisis, kejahatan kekerasan seksual pada anak, mayoritas dilakukan oleh orang yang dikenal oleh korban dan dilakukan dengan cara menbujuk atau ancaman.
\end{abstract}

Keywords: sexual child abuse, perpetrators, Victim

PSIKOISLAMIKA. Jurnal Psikologi Islam (JPI) copyright @ 2015 Pusat Penelitań dan Layanan Psikologi. Volume 12. Nomor 2, Tahun 2015

\section{PENDAHULUAN}

Tingkah laku kriminal kekerasan seksual memiliki tingkat kuantitas yang cukup tinggi di Indonesia, dan tak jarang yang menjadi korban dalam kasus kriminalitas jenis ini adalah anak yang usianya masih dibawah umur. Menurut data yang dikumpulkan oleh Kementrian Koordinator Bidang Kesejahteraan Rakyat dari tahun 2010 hingga tahun 2014 tercatat sebanyak 21.869.797 kasus kekerasan seksual anak, yang tersebar di 34 provinsi, dan 179 kabupaten dan kota. Sebesar 42-58\% dari pelanggaran hak anak itu, katanya, merupakan kejahatan seksual terhadap anak (kemenkopmk.com). Artinya kasuskasus ini banyak sekali dijumpai meskipun tidak secara langsung.

Mirisnya, sebagian besar pelaku pelecahan seksual adalah orang yang dikenal oleh korban mereka; sekitar $30 \%$ adalah keluarga dari si anak, paling sering adalah saudara laki-laki, ayah, paman, atau sepupu; sekitar $60 \%$ adalah kenalan lainnya seperti 'teman' dari keluarga, pengasuh, atau tetangga, orang asing adalah pelanggar sekitar $10 \%$ dalam kasus penyalahgunaan seksual anak (Whealin, 2007).

Finkelhor (1999) menyebutkan bahwa, di Amerika Utara epidemiologi tren pelecehan seksual secara teoritis dibagi menjadi lima Kategori: penyalahgunaan intrafamilial, melibatkan ayah, figur ayah, paman atau kakak; penganiayaan yang dilakukan oleh pengasuh, seperti guru, rohaniwan dan pelatih; anak-anak dianiaya secara seksual atau diperkosa oleh pelanggar muda yang sendiri adalah bawah umur. Sedangkan korbannya yaitu perempuan dan anak-anak yang dieksploitasi di pasar sebagai pekerja seks komersial. Sejumlah Studi telah mengkonfirmasi bahwa banyak dari penyalahgunaan dilakukan oleh anggota keluarga 
(Paulauskas:2013).

Pelecehan seksual anak (Child Sexual Abuse) melibatkan membujuk atau memaksa seorang anak untuk ambil bagian dalam kegiatan seksual, atau mendorong seorang anak untuk berperilaku dalam seksual yang tidak pantas termasuk selesai atau berusaha tindakan seksual atau hubungi atau interaksi seksual non-kontak dengan seorang anak oleh orang dewasa. Ini mungkin mengambil beberapa bentuk: penetrasi - antara mulut, penis, vulva anus dari anak dan individu lain: kontakdisengaja menyentuh alat kelamin, pantat, atau payudara dengan atau tanpa pakaian (tidak termasuk perawatan normal): non-kontak- terhadap paparan pada aktivitas seksual, pembuatan film, prostitusi (Molyneux, dkk:2013).

Ada beberapa alasan mengapa anak sering kali menjadi target kekerasan seksual yaitu: anak selalu berada pada posisi yang lebih lemah dan tidak berdaya, moralitas masyarakat khususnya pelaku kekerasan seksual yang rendah, kontrol dan kesadaran orang tua dalam mengantisipasi tindak kejahatan pada anak yang rendah. (Hertinjung: 2009) dari beberapa penelitian yang telah ada sebelumnya dapat dilihat bahwa jarang kekerasan seksual terhadap anak dilakukan oleh orang asing (tidak dikenal oleh korban). Oleh karena itu kami ingin mengetahui lebih lanjut siapakah yang berpotensi menjadi pelaku kekerasan seksual pada anak.

Berdasarkan uraian diatas, penelitian ini bertujuan untuk mengetahui relasi pelaku-korban dan modes pelaku kekerasan seksual pada anak. Dari penelitian ini dapat membuka wacana bahwa potensi terjadinya kekerasan seksual dapat dilakukan oleh orang-orang yang dikenal bahkan yang telah sangat dipercaya dan memberikan kewaspadaan bagi masyarakat semua.

\section{KERANGKA KERJA TEORITIK}

Kekerasan seksual pada anak dibawah umur sudah menjadi ancaman di Indonesia, melonjaknya kekerasan seksual di Indonesia membuat semua orang harus waspada karna kekerasan seksual merupakan salah satu bentuk penyiksaan terhadap anak, dimana orang dewasa atau remaja menggunakan anak sebagai rangsangan seksual. Bentuk pelecehan seksual pada anak termasuk meminta atau menekan seorang anak untuk melakukan aktivitas seksual, memberikan paparan yang tidak selayaknya untuk ditampilkan pada anak. Berikut terdapat beberapa istilah-istilah tentang kekerasan seksual, diantaranya:

Menurut WHO (dalam Lidya, 2009) kekerasan terhadap anaka adalah suatu penganiayaan atau perlakuan salah pada anak dalam bentuk menyakiti fisik, emosional, seksual melalaikan pengasuhan dan eksploitasi untuk kepentingan komersial yang secara nyata ataupun tidak dapat membahayakan kesehatan, kelangsungan hidup, martabat atau pengembangannya, tindakan kekerasan diperoleh dari orang yang bertanggung jawab, dipercaya atau berkuasa dalam perlindungan anak tersebut.

Anak adalah setiap manusia yang berusia dibawah 18 tahun, termasuk anak yang masih dalam kandungan (UU no.23 tahun 2002 tentang perlindungan anak). Kekerasan seksual adalah setiap bentuk perilaku yang memiliki muatan yang dilakukan seseorang atau sejumlah orang, namun tidak disukai dan tidak di harapkan oleh orang yang menjadi sasaran sehingga menimbulkan akibat negatif seperti ras malu, tersinggung, terhina, marah, kehilangan harga diri, kehilangan kesucian, dan sebagainya pada orang yang menjadi korban (Supardi \& Sadarjoen, 2006).

\section{Pasal-Pasal Perlindungan Anak}

Perlindungan anak merupakan segala kegiatan untuk menjamin dan melindungi anak dan hak-hak agar dapat hidup, tumbuh dan berkembang dan berpartisipasi secara optimal serta mendapatkan perlindungan dari kekerasan dan diskriminasi. Pelecehan seksual terhadap anak perlu mendapatkan perhatian serius mengingat akibat dari kekerasan seksual terhadap anak akan menyebabkan anak mengalami trauma yang berkepanjangan. Upaya perlindungan anak harus dimulai sedini mungkin. Di Indonesia kekerasan seksual pada anak dapat dihukum seperti dalam UU No. 23 tahun 2002 tentang Perlindungan Anak yang termuat dalam Bab XII yaitu mulai Pasal 77 sampai dengan Pasal 90 serta UU No. 39 tahun 1999 tentang HAM Pasal 65 mengatur tentang adanya hak anak untuk mendapatkan perlindungan dari kegiatan eksploitasi dan pelecehan seksual, penculikan, perdagangan anak serta dari berbagai bentuk penyalah gunaan narkotika, psikotropika, dan zat adiktif lainnya.

Dalam UU No. 23 tahun 2002 Pasal 88 mengatur adanya ketentuan pidana bagi setiap orang yang mengeksploitasi ekonomi ataupun seksual anak dengan maksud menguntungkan diri sendiri atau orang lain, dipidana dengan pidana penjara paling lama 10 tahun dan/atau denda paling banyak Rp200.000.000,00 (dua ratus juta rupiah).

Kekerasan seksual pada anak adalah hubungan atau interaksi antara seorang anak dengan orang yang 
lebih tua atau orang yang lebih dewasa seperti orang asing, saudara sekandung atau orang tua dimana anak tersebut dipergunakan sebagai sebuah objek pemuas bagi kebutuhan seksualnya. Perbuatan itu dilakukan dengan menggunakan paksaan, ancaman, suap, tipuan maupun tekanan.

Anak korban kejahatan seksual mempunyai kebutuhan yang berbeda dengan korban kejahatan yang lain pada umumnya. Beberapa faktor yang membedakan, sebagai berikut; 1 ). Tingkat dan bentuk pengalamam trauma. 2). Anak-anak merupakan pihak yang rawan menjadi korban penyerangan 3). Tekanan sosial dari orang dewasa terhadap anakanak korban kejahatan yang kurang berdaya. 4). Dukungan sosial terhadap pelaku kejahatan

Hubunngan dekat antara korban dan pelaku sering menambah kompleksitas dari penanganan kasus kejahatan seksual pada anak. Berbagai bentuk dukungan khusus dibutuhkan untuk membantu anak yang menjadi korban kejahatan seksual.

Kasus kekerasan seksual pada anak merupakan salah satu jenis kasus yang masuk Berita Acara Persidangan (BAP). BAP dalam penelitaian merupakan hasil putusan dari Mahkamah Agung tentang kasuskasus kasasi. . Dalam BAP berisikan tentang kasuskasus yang telah naik banding dipengadilan dan telah diputuskan oleh Mahkamah Agung. Dalam BAP banyak dijelaskan tentang bagaimana kasus itu terjadi, dimana kejadiannya, siapa pelakunya, alasan melakukan perbuatan tersebut dan hukuman yang diberikan sesuai dengan kejahatan yang dilakukan semuanya dijelaskan dalam BAP. Oleh karena itu, untuk meneliti sebesar apakah kekerasan seksual pada anak itu terjadi, kami menggunakan BAP sebagai bahan pengumpulan data untuk memperoleh data valid dari seberapa besar potensi kekerasan seksual pada anak dibawah umur itu terjadi.

\section{METODE}

Peneltian ini menggunakan pendekatan deskriptif kualitatif yang bertujuan untuk meringkas serta menggambarkan kondisi, situasi dan fenomena yang menjadi realitas sosial dalam masyarakat. lebih spesifik lagi, metode pendekatan ini bertujuan untuk mengangkat ciri, karakter, sifat, model atau gambaran yang lebih spesifik tentang objek penelitian yaitu kasus kekerasan seksual pada anak.

Untuk proses analisis data, penelitian ini menggunakan metode archival research atau yang lebih dikenal dengan metode penelitian arsip. Metode penelitian arsip ini adalah sebuah metode penelitian menggunakan arsip, data atau dokumen yang sudah ada yang kemudian digunakan untuk menggali informasi dalam proses penelitian (Shelly: 2009). Yang dimaksud Data yang sudah ada di dalam penelitian ini adalah arsip berupa BAP (Berita Acara Pemeriksaan) dari kasus MA (Mahkamah Agung). Arsip BAP tersebut kemudian dijadikan sebagai sumber informasi primer dalam proses analisis data penelitian. Penelitian ini mengambil sampel kasus yang serupa, yakni kekerasan seksual pada anak, sebanyak 16 kasus dengan setting tempat dan situasi yang berbeda satu sama lain.

Enam belas kasus tersebut diringkas dalam sebuah tabel yang akan disajikan dan dijabarkan pada tahap penjabaran hasil penelitian nantinya. Peneliti mengamati setiap kasus dari beberapa segi yakni pelaku, usia pelaku, jenis kelamin pelaku, relasi dengan korban, siapa yang menjadi korban dan bagaimana cara pelaku memperlakukan korban. Tujuan dari pengamatan tersebut adalah untuk mengetahui tingkat potensi terjadinya kekerasan seksual pada anak.

\section{HASIL DAN PEMBAHASAN}

Berdasarkan 16 kasus yang dianalisis menggambarkan bahwa potensi kekerasan seksual dapat terjadi di manapun dan dapat dilakukan oleh siapapun bahkan oleh seseorang yang dekat dengan korban. 
Tabel 1. Hasil analisis kategori kasus kekerasan seksual pada BAP

\begin{tabular}{|c|c|c|c|c|c|c|c|c|}
\hline No. & No. Putusan & $\begin{array}{l}\text { Pelaku/ Usia/ } \\
\text { JK }\end{array}$ & Pekerjaan & $\begin{array}{l}\text { Relasi dg } \\
\text { Korban }\end{array}$ & $\begin{array}{l}\text { Korban/ } \\
\text { Usia }\end{array}$ & $\mathbf{F}$ & $\begin{array}{l}\text { Tempat } \\
\text { Kejadian }\end{array}$ & Keterangan \\
\hline 1 & $\begin{array}{l}\text { 54/Pid. } \\
\text { Sus/2013/ } \\
\text { PN.Rkb }\end{array}$ & $\begin{array}{l}\text { Mamat/60 } \\
\text { Thn/LK }\end{array}$ & Petani & Terapis & $\begin{array}{l}\mathrm{S} M / 12 \\
\text { Thn }\end{array}$ & 3 & $\begin{array}{l}\text { Rumah } \\
\text { Korban }\end{array}$ & $\begin{array}{l}\text { Korban Mengidap } \\
\text { Epilepsi dan } \\
\text { perilaku tidak } \\
\text { senonoh itu } \\
\text { disangka bagian dari } \\
\text { ritual pengobatan } \\
\end{array}$ \\
\hline 2 & $\begin{array}{l}60 \text { PK/Pid. } \\
\text { Sus/2011 }\end{array}$ & $\begin{array}{l}\text { C V H/42 } \\
\text { Thn/LK }\end{array}$ & $\begin{array}{l}\text { Swasta } \\
\text { (pegawai } \\
\text { toko) }\end{array}$ & Tetangga & $\begin{array}{l}\text { HF/ } 5 \\
\text { Thn }\end{array}$ & 1 & $\begin{array}{l}\text { Rumah } \\
\text { Terdakwa }\end{array}$ & $\begin{array}{l}\text { Korban diberikan } \\
\text { uang Rp. } 1,000,- \\
\text { setelah kejadian }\end{array}$ \\
\hline 3 & $\begin{array}{l}67 / \\
\text { Pid.B/2011/ } \\
\text { PN-NBE }\end{array}$ & $\begin{array}{l}\text { YM/ } 26 \mathrm{Thn} / \\
\text { LK }\end{array}$ & Nelayan & Tetangga & $\begin{array}{l}\text { YA/ } 13 \\
\text { Thn }\end{array}$ & 1 & $\begin{array}{l}\text { Rumpun } \\
\text { Pisang } \\
\text { Belakang } \\
\text { Rumah Pelaku } \\
\end{array}$ & $\begin{array}{l}\text { Percobaan } \\
\text { Pemerkosaan }\end{array}$ \\
\hline 4 & $\begin{array}{l}\text { 146/ } \\
\text { Pid.B/2013/ } \\
\text { PN.PSB }\end{array}$ & & Swasta & $\begin{array}{l}\text { Orang yg } \\
\text { dikenal }\end{array}$ & $\begin{array}{l}\mathrm{NH} / 16 \\
\text { Thn }\end{array}$ & 1 & $\begin{array}{l}\text { kamar kos } \\
\text { korban }\end{array}$ & $\begin{array}{l}\text { korban diancam } \\
\text { dengan pisau }\end{array}$ \\
\hline 5 & $\begin{array}{l}05 \text { / Pid.Sus / } \\
2012 \text { / PN.BTG }\end{array}$ & & Buruh & $\begin{array}{l}\text { Ayah kandung } \\
\text { korban }\end{array}$ & $\begin{array}{l}\text { IP / } 15 \\
\text { Thn }\end{array}$ & 3 & $\begin{array}{l}\text { kamar korban } \\
\text { (rumah } \\
\text { pelaku) }\end{array}$ & $\begin{array}{l}\text { sang isteri } \\
\text { (ibukorban) } \\
\text { berkerja merantau } \\
\text { di jakarta korban } \\
\text { diancam tidak } \\
\text { diberikan uang } \\
\text { jajan }\end{array}$ \\
\hline 6 & $\begin{array}{l}\text { 07/PID/2013/ } \\
\text { PT.Mdn }\end{array}$ & $\begin{array}{l}\text { IS/ } 50 \text { Thn/ } \\
\text { laki-laki }\end{array}$ & $\begin{array}{l}\text { Pencari } \\
\text { barang bekas }\end{array}$ & Ayah + anak tiri & $\begin{array}{l}\text { WN / } 16 \\
\text { Thn }\end{array}$ & 1 & $\begin{array}{l}\text { rumah korban } \\
\text { dan pelaku }\end{array}$ & $\begin{array}{l}\text { Pelaku juga sempat } \\
\text { mengancam NN } \\
\text { selaku adik korban } \\
\text { yang sempat } \\
\text { memergoki } \\
\text { perbuatannya }\end{array}$ \\
\hline 7 & $\begin{array}{l}\text { 143/Pid. } \\
\text { Sus/2012/ } \\
\text { PN.JMB }\end{array}$ & $\begin{array}{l}\text { M / } 29 \text { Thn / } \\
\text { laki-laki }\end{array}$ & PNS & Ayah + anak tiri & $\begin{array}{l}\text { NA / } 9 \\
\text { Thn }\end{array}$ & & $\begin{array}{l}\text { Ruang tamu } \\
\text { Rumah } \\
\text { korban dan } \\
\text { pelaku }\end{array}$ & $\begin{array}{l}\text { pelaku tidak sampai } \\
\text { merusak selaput } \\
\text { dara korban }\end{array}$ \\
\hline 8 & $\begin{array}{l}\text { 16/ } \\
\text { PID.B/2013/ } \\
\text { PN.BK }\end{array}$ & $\begin{array}{l}\text { A / } 26 \text { Thn / } \\
\text { laki-laki }\end{array}$ & Petani & Tetangga & A / 8 Thn & 1 & $\begin{array}{l}\text { Ruang televisi } \\
\text { rumah pelaku }\end{array}$ & \\
\hline 9 & $\begin{array}{l}\text { 81/Pid. } \\
\text { Sus/2014/ } \\
\text { PT.Smg }\end{array}$ & $\begin{array}{l}\text { S / } 46 \text { Thn / } \\
\text { laki-laki }\end{array}$ & Wiraswasta & Kakek + cucu & $\begin{array}{l}\text { RA / } 6 \\
\text { Thn }\end{array}$ & 1 & $\begin{array}{l}\text { Ruang televisi } \\
\text { rumah pelaku } \\
\text { dan korban }\end{array}$ & $\begin{array}{l}\text { Pelaku menjanjikan } \\
\text { jajanan terhadap } \\
\text { korban }\end{array}$ \\
\hline 10 & $\begin{array}{l}122 / \\
\text { Pid.B/2013/ } \\
\text { PN. Stb }\end{array}$ & $\begin{array}{l}\text { B, R, F, dan } \\
\text { I / Sekitar } \\
\text { 30-40 Thn/ } \\
\text { laki-laki }\end{array}$ & Pengangguran & $\begin{array}{l}\text { Orang asing } \\
\text { (rampok) }\end{array}$ & $\begin{array}{l}\text { PD / } 16 \\
\text { Thn }\end{array}$ & 1 & Kamar korban & $\begin{array}{l}\text { Tujuan utama Ke } \\
\text { empat pelaku } \\
\text { sebenarnya berniat } \\
\text { untuk merampok } \\
\text { rumah korban. }\end{array}$ \\
\hline 11 & $\begin{array}{l}\text { XXX K/PID. } \\
\text { SUS/XXXXX }\end{array}$ & $\begin{array}{l}\text { AD/ } 37 \text { Thn/ } \\
\text { LK }\end{array}$ & Swasta & Tetangga & $\begin{array}{l}\text { AK/ } 6 \\
\text { Thn }\end{array}$ & 1 & $\begin{array}{l}\text { Sofa, Ruang } \\
\text { Tengah }\end{array}$ & $\begin{array}{l}\text { Korban didekati } \\
\text { saat bermain game }\end{array}$ \\
\hline 12 & $\begin{array}{l}\text { 94/Pid. } \\
\text { Sus/2014/PT } \\
\text { JAP }\end{array}$ & $\begin{array}{l}\text { DR/ } 20 \text { Thn/ } \\
\text { LK }\end{array}$ & Pengangguran & Kekasih & $\begin{array}{l}\text { NA/ } 16 \\
\text { Thn }\end{array}$ & 5 & $\begin{array}{l}\text { Dalam kamar } \\
\text { rumah } \\
\text { kerabat } \\
\text { korban }\end{array}$ & $\begin{array}{l}\text { Membujuknya } \\
\text { untuk melakukan } \\
\text { hubungan secara } \\
\text { berkelanjutan }\end{array}$ \\
\hline 13 & $\begin{array}{l}\text { 108/Pid. } \\
\text { Sus/2014/ } \\
\text { PN.Kot. }\end{array}$ & $\begin{array}{l}\text { XX/ } 55 \text { Thn/ } \\
\text { LK }\end{array}$ & PNS & Kerabat & $\begin{array}{l}\text { AM/ } 16 \\
\text { Thn }\end{array}$ & - & $\begin{array}{l}\text { Kamar } \\
\text { terdakwa }\end{array}$ & $\begin{array}{l}\text { Membujuknya } \\
\text { membelikan Ipad }\end{array}$ \\
\hline 14 & $\begin{array}{l}\text { 123/Pid. } \\
\text { Sus/2014/ } \\
\text { PN.Cj. }\end{array}$ & CG/ & $\begin{array}{l}\text { Pemandu } \\
\text { Lagu }\end{array}$ & Guru & $\begin{array}{l}\text { I/ } 14 \\
\text { Thn/ }\end{array}$ & - & Hotel Bydiel & $\begin{array}{l}\text { Dibujuuk dengan } \\
\text { memberi uang } \\
\text { sebesar } 100 \mathrm{Rb}\end{array}$ \\
\hline
\end{tabular}




\begin{tabular}{|c|c|c|c|c|c|c|c|c|}
\hline 15 & $\begin{array}{l}\text { 149/ } \\
\text { Pid.A/2013/ } \\
\text { PN.GS }\end{array}$ & MS/ & Pelajar & Teman & $\begin{array}{l}\text { WA/ } 16 \\
\text { Thn }\end{array}$ & 1 & $\begin{array}{l}\text { Basecame } \\
\text { Ekstrakulikuler } \\
\text { di Sekolah }\end{array}$ & $\begin{array}{l}\text { Membujuknya } \\
\text { dengan mengatakan } \\
\text { bahwa dia tidak } \\
\text { akan hamil }\end{array}$ \\
\hline 16 & $\begin{array}{l}\text { 292/Pid. } \\
\text { Sus/2012/PN. } \\
\text { SGR }\end{array}$ & $\begin{array}{l}\mathrm{JJ} / 57 \text { tahun } \\
\text { / laki2 }\end{array}$ & $\begin{array}{l}\text { Teknisi } \\
\text { bangunan }\end{array}$ & Orang asing & $\begin{array}{l}\text { KA, KR, } \\
\text { LM dan } \\
\text { PS/ } 14 \\
\text { tahun }\end{array}$ & 3 & $\begin{array}{l}\text { Di rumah } \\
\text { korban }\end{array}$ & $\begin{array}{l}\text { Pelaku kadangkala } \\
\text { melakukannya pada } \\
3 \text { korban sekaligus } \\
\text { dalam satu waktu } \\
\text { karna keempat } \\
\text { korban berteman } \\
\text { akrab }\end{array}$ \\
\hline
\end{tabular}

Tabel analisis menggabarkan bahwa kejahatan terhadap anak-anak terutama kekerasan seksual dilakukan oleh pelaku yang lebih dewasa dengan modus yang berbagai macam. Ada yang menggunakan cara membujuk korban dengan dijanjikan imbalan sejumlah uang, membelikan sesuatu yang diinginkan korban, atau memang dengan cara mengancam atau memaksa. Melalui modus-modus tersebut, kemudian pelaku melakukan kejahatan tersebut ditempat yang dirasa aman. Terdapat 12 kasus kejahatan kekerasan seksual yang dilakukan di rumah milik korban ataupun pelaku, 2 kasus kejahatan kekerasan seksual lainnya dilakukan di tempat-tempat yang biasa didatangi oleh korban seperti sekolah, rumah kerabat, 2 kasus sisanya terjadi ditempat yang tidak biasa dikunjungi oleh korban seperti halnya hotel dan rerumpunan pisang.

Ditinjau dari hubungan pelaku dengan korban, diketahui bahwa dari 16 sampel kasus kejahatan kekerasan seksual yang telah dipaparkan pelaku kejahatan hanya 1 sampel kasus yang dilakukan oleh orang tidak dikenal oleh korban dan 15 sisanya dilakukan oleh seseorang yang dikenal oleh korban seperti teman, pacar, tetangga, guru, bahkan ada pelaku yang merupakan keluarga dekat korban seperti ayah kadung, ayah tiri dan kakek korban.

Sebagaimana dijabarkan di atas bahwa anak-anak mudah sekali untuk dibujuk, dengan iming-iming makanan atau mainan. Selain itu anak-anak sering kali tidak mempunyai keberanian untuk menolak, terutama pada orang yang dikenalnya. Hal ini tak terlepas dari cara berfikir anak yang cenderung pragmatis dan sederhana dalam menganalisa.

Tentu dengan kondisi ini peran orang tua menjadi sangat penting untuk melindungi anakanak agar tidak menjadi korban kejahatan seksual. kewaspadaan ini tidak hanya cukup pada orangorang asing semata tetapi juga pada yang paling dekat sekalipun seperti orang tua kandung maupun orang lain yang dikenal oleh anak. .

\section{Pengaruh Lingkungan}

Lingkungan memiliki pengaruh yang sangat dominan dalam segala tingkah laku individu termasuk pelaku kekerasan seksual. Setting lingkungan tidak hanya berpengaruh secara fisik tapi juga secara psikologis dan sosial bagi masyarakat di dalamnya. Survei menunjukkan bahwa sekitar tiga perempat dari pelaku kejahatan seks remaja di lembaga pemasyarakatan memiliki sejarah masa kecil hubungan keluarga miskin, pemisahan orang tua atau kerugian, penempatan asuh, fisik atau pelecehan seksual, dan penelantaran (Boswell, 1995; Falshaw \& Browne, 1997). Ini menunjukkan bahwa ligkungan tempat individu hidup dan di besarkan sangat mempengaruhi perilaku individu tersebut dikemudian hari. Setting lingkungan yang tepat akan mendukung kesejahteraan individu-individu yang berada didalamnya, dan sebaliknya setting lingkungan yang kurang tepat akan menghambat kesejahteraan hidup individu-individu didalamnya.

Kondisi moralitas masyarakat dalam sebuah lingkungan juga mempengaruhi potensi kekerasan seksual secara signifikan (Hertinjung: 2009), karena ditinjau dari segi pelaku yang melakukan kekerasan seksual pada anak. individu dengan kesadaran moralitas tinggi tidak akan melakukan kekerasan seksual atau kejahatan lain kepada anak maupun orang lain disekitarnya.

\section{Mengapa anak dijadikan sebagai objek kekerasan seksual ?}

Finkelhor (1999) menunjukkan bahwa anak dari kelompok tertentu lebih rentan terhadap pelecehan seksual dibandingkan dengan yang lainnya. Mereka termasuk anak-anak dari keluarga yang bercerai, anak yang hidup dengan orang tua tiri atau wali, anak-anak dari keluarga yang melakukan kekerasan, cacat fisik seperti kecanduan alkohol, obat-obatan dan masalah kesehatan mental (Paulauskas: 2013). Sebuah studi di india juga melaporkan bahwa terdapat beberapa anak yang rentan menjadi korban 
pelecehan seksual diantaranya anak-anak jalanan, anak-anak yang berada di lembaga pengasuhan anak, anak yang mengalami kesulitan ekonomi, anak tiri dan anak yatim yang miskin (Molyneux, dkk :2013). Penelitian tersebut dapat diketahui bahwa Anak yang menjadi objek kekerasan seksual cenderung lebih lemah baik secara fisik, psikologis, ekonomi maupun sosial dibandingkan dengan pelaku, sehingga mereka cenderung tidak memiliki kemampuan untuk menentang atau melawan pelaku kejahatan tersebut.

\section{KESIMPULAN}

Berdasarkan penjelasan di atas, dapat dibuktikan bahwa kekerasan seksual marak dilakukan oleh orang-orang dewasa kepada anak-anak dibawah umur. Potensi lebih banyak terjadi pada anakanak dibawah umur, ini dikarenakan anak-anak memiliki power yang lemah, baik itu fisik maupun psikis mereka. Sehingga potensi kekerasan seksual lebih besar terjadi pada anak-anak dibawah umur daripada orang dewasa.

Kasus kekerasan seksual pada anak yang dijelaskan dalam BAP, kebanyakkan anak-anak ada yang dibujuk rayu dengan mainan, jajan ataupun uang dan ada juga yang dipaksa. Pada dasarnya kasus kekerasan seksual pada anak yang dilakukan

\section{DAFTAR PUSTAKA}

Eric Wood, Shelley Riggs (2009). Adult Attachment, Cognitive Distortions, and Views of Self, Others, and the Future Among Child Molesters. A journal of research and treatment 21, 375-390.

Sharon M; Lewis, Kathy; Sigal, Janet (2004). The Impact of Risk Factors on the Treatment of Adolescent Sex Offenders Kelley. Journal of Addictions \& Offender Counseling 24, 67-81.

Amy C. Tishelman, Susanne K. Meyer, Penny Haney, Sara K. McLeod, (2010). The Clinical-Forensic Dichotomy in Sexual Abuse Evaluations: Moving Toward an Integrative Model. Journal of Child Sexual Abuse, 19, 590-608.

Catherine Townsend (2013). Estimating a Child Sexual Abuse Prevalence Rate for Practitioners. $A$ Review of Child Sexual Abuse: Prevalence Studies

Natalia D. Tapia (2014). Survivors of Child Sexual Abuse and Predictors of Adult Re-victimization in the United States: A Forward Logistic oleh orang-orang yang tidak bertanggung jawab, dapat menyebabkan trauma mendalam pada korban pelecehan seksual dan dapat mengganggu jiwanya dan merusak masa depan anak tersebut.

Berdasarkan 16 kasus telah dianalisis ter bahwa kebanyakkan kekerasan seksual dilakukan pada anak-anak dibawah umur dan pelakunya merupakan orang-orang terdekat korban. Oleh karena itu, sebagai orang tua dan orang-orang terdekat, harus lebih waspada dalam melihat cara pergaulan anak dan lingkungan sekitarnya, untuk mewaspadai timbulnya kekerasan seksual yang mengakibatkan anak-anak akan mengalami masa-masa suram dan tidak bisa melihat masa depan mereka hanya karena perbuatan yang tidak manusiawi oleh orang-orang yang tidak bertanggung jawab.

Hasil ini menegaskan kembali bahwa siapapun bisa mnejadi pelaku kejahatan seksual, hal ini meniscayakan kewaspadaan pada lingkungan merupakan cara yang paling ampuh untuk menanggulang kekerasan seksual pada anak. Dengan pelaku orang dekan seperti ini tentu sering kali menimbulkan efek trauma yang berkepanjangan jika tidak ditangani dengan baik untuk itu diperlukan penangana yang komprehensif yang berorientasi pada restorasi korban dengan lebih sungguh-sungguh.

Regression Analysis. Journal of criminal justice sciences. 9, 64-73.

Elizabeth M. Molyneux, Neil Kennedy, Asefa Dano, Yabwile Mulambia (2013). Sexual abuse of children in low-income settings: time for action. Paediatrics and International Child Helath. 33, 239-246.

Rolandas Paulauskas (2013). Sexual Deviance And Child Abuse. Teacher Education. 21, 10-23.

Michael H. Miner, Beatrice "Bean" E. Robinson, Raymond A. Knight, Dianne Berg, Rebecca Swinburne Romine and Jason Netland (2010). Understanding Sexual Perpetration Against Children: Effects of Attachment Style, Interpersonal Involvement and Hypersexuality. A Journal Of Research and Treatment. 22, 58-77.

Taylor E., Shelly, Peplau Anna Letitia, Sears O., David (2009). Psikologi Sosial Edisi Kedua Belas. Jakarta: Kencana Prenada Media Group

Kelley, Sharon M; Lewis, Kathy; Sigal, Janet. Journal of Addictions \& Offender Counseling 24.Â 2 (Apr 2004): 67-81. 